\title{
A valorização dos professores e a educação básica nos estados
}

Gisele MAsson*

RESUMO: O artigo apresenta um panorama geral da situação dos professores nas redes estaduais de ensino, por meio de pesquisa documental, que mostra a discrepância na remuneração nos anos finais do ensino fundamental e ensino médio, evidenciando a urgência de encarar a valorização desses profissionais, essencial $\boldsymbol{a}$ melhoria da qualidade da educação.

Palavras-chave: Política educacional. Valorização de professores. Planos de carreira.

\section{Introdução}

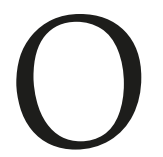

tema da valorização de professores tem recebido visibilidade no âmbito acadêmico, político ou sindical. Isso se deve, especialmente, à aprovação da Lei no 11.738, de 2008, a qual instituiu um Piso Salarial Profissional Nacional (PSPN), gerando uma série de controvérsias, como a Ação Direta de Inconstitucionalidade (ADIn n 4167), conduzida pelos governadores de Mato Grosso do Sul, Rio Grande do Sul, Paraná, Ceará e Santa Catarina, e com apoio posterior dos estados de Roraima, São Paulo, Tocantins, Minas Gerais e Distrito Federal. Em que pese o fato de a Adin ter sido julgada improcedente, ainda há estados que não cumprem com a lei do piso, contribuindo para manter o quadro de desvalorização dos professores no Brasil.

Quando nos referimos à valorização de professores, entendemos o envolvimento de três dimensões fundamentais: condições de trabalho, remuneração e carreira, formação

\footnotetext{
Doutora em Educação. Professora do Departamento de Educação e do Programa de Pós-Graduação em Educação da Universidade Estadual de Ponta Grossa (UEPG). Coordena o Grupo de Pesquisa Capital, Trabalho, Estado e Educação: Políticas Educacionais e Formação de Professores. Membro da Associação Nacional pela Formação dos Profissionais da Educação (Anfope) e do Conselho Acadêmico da Red Latinoamericana de Estudios Epistemológicos en Política Educativa (Relepe). Ponta Grossa/PR - Brasil. Email:<gimasson@uol.com.br>.
} 
inicial e continuada. Todavia, a questão da remuneração é fator decisivo para a permanência no magistério, uma vez que a garantia da existência humana depende, em primeira instância, do acesso aos bens necessários à satisfação das necessidades históricas, o que depende essencialmente do recebimento de um salário compatível.

Marx e Engels (2007, p.33) enfatizaram que “[...] o primeiro fato histórico é, pois, a produção dos meios para a satisfação dessas necessidades, a produção da própria vida material." Além disso, "[...] a satisfação dessa primeira necessidade, a ação de satisfazê-la e o instrumento já adquirido conduzem a novas necessidades." Desse modo, de acordo com os autores, a primeira coisa a se fazer em qualquer concepção histórica da realidade é observar a questão de como se dá a satisfação das necessidades humanas, pelo trabalho, em toda a sua significação e alcance.

Buscamos, portanto, apresentar neste artigo o vencimento inicial e a remuneração final dos professores que atuam nas redes estaduais de ensino no Brasil. Primeiramente, destacamos o conjunto de dispositivos legais e normativos que regulamentam o salário e as carreiras dos professores. Na sequência, apresentamos, com base em dados de pesquisa, a realidade da remuneração docente nos estados brasileiros e, por último, problematizamos as disparidades entre eles.

\section{Aspectos legais e normativos da remuneração docente}

A discussão sobre remuneração de professores tem sido mais frequente na última década, todavia, a preocupação com essa questão já se fazia presente, no âmbito legal, desde a década anterior. Pretendemos apresentar o conjunto de leis e atos normativos que regulamentam diretamente a carreira e o salário dos professores no Brasil. Elaboramos uma síntese da regulamentação a ser considerada, quando nos referimos à valorização de professores:

» Constituição Federal, de 1988, Art. 206, Inciso V, Redação dada pela Emenda Constitucional n 53, de 2006: estabelece a garantia de planos de carreira e ingresso exclusivamente por concurso público.

» Lei de Diretrizes e Bases da Educação Nacional (LDBN), de 1996, Art. 67: assegura planos de carreira, ingresso exclusivamente por concurso público, licenciamento para aperfeiçoamento profissional continuado, piso salarial, progressão funcional baseada na titulação ou habilitação, e na avaliação do desempenho, hora-atividade e condições adequadas de trabalho.

» Resolução CNE/CBE nº 3, de 1997: definição de Diretrizes para os Planos de Carreira e Remuneração para o Magistério dos estados, do Distrito Federal e dos municípios. 
» Lei nº 11.494, de 2007, Art. 22: dispõe sobre a parcela da verba do Fundo de Manutenção e Desenvolvimento da Educação Básica e Valorização do Magistério (FUNDEB) destinada ao pagamento dos profissionais do magistério.

» Lei n⿳⺈ 11.738, de 2008: instituição do Piso Salarial Profissional Nacional para os profissionais do magistério público da Educação Básica e limite máximo de 2/3 (dois terços) da carga horária para o desempenho de atividades de interação com os alunos (hora-atividade).

» Resolução CNE/CEB nº 2, de 2009, Art. 3º: estabelece Diretrizes Nacionais para os Planos de Carreira e Remuneração dos Profissionais do Magistério da Educação Básica Pública.

» Lei nº 13.005, de 2014, Plano Nacional de Educação (PNE): determina que os estados e os municípios implementem ou revisem os seus planos de carreira até 2016; indica a necessidade de implantação gradual do cumprimento da jornada de trabalho em um único estabelecimento escolar, previsão de licenças remuneradas e incentivos para qualificação profissional e o acompanhamento do cumprimento do PSPN.

Diante desse conjunto de normas e leis, há garantias jurídicas suficientes para que o professor tenha condições de trabalho, possibilidade de formação e remuneração mínima. Contudo, a lei não faz a realidade, impondo a necessidade de pesquisas que evidenciam como vem ocorrendo a valorização do professor no Brasil.

Gouveia e Souza (2015, p. 40) destacam que:

[...] compreender as condições de carreira e remuneração dos professores brasileiros implica em situá-los nos contextos que resultam de disputas nacionais e locais que conformam as condições, ou ausência de condições, para garantia da valorização desses profissionais, e requer analisar tais condições em contextos concretos de disputa em cada uma das unidades federadas que compõe o complexo sistema educacional brasileiro.

Assim, a análise das condições concretas da remuneração dos professores nas diferentes unidades federativas é fundamental para que seja possível contribuir com dados para a gestão da educação e a organização dos sindicatos e movimentos sociais que atuam em defesa da valorização desses profissionais.

A regulamentação dos planos de carreira dos professores não tem garantido uma isonomia entre eles, pois cada estado define critérios e formatos que dificultam a valorização de forma correspondente com a formação e o tempo de exercício na profissão. Além do mais, há uma disparidade muito grande entre a remuneração de professores e a de outras profissões com a mesma formação. 
Com base na Pesquisa Nacional por Amostra de Domicílios (Pnad), o Observatório do PNE considerou o rendimento médio dos professores da educação básica com formação em nível superior em comparação com o rendimento médio de outros profissionais com a mesma titulação. O gráfico a seguir explicita a diferença entre esses rendimentos.

\section{Gráfico 1 - Rendimento médio dos professores de Educação Básica em relação ao rendimento médio dos demais profissionais com Educação Superior}

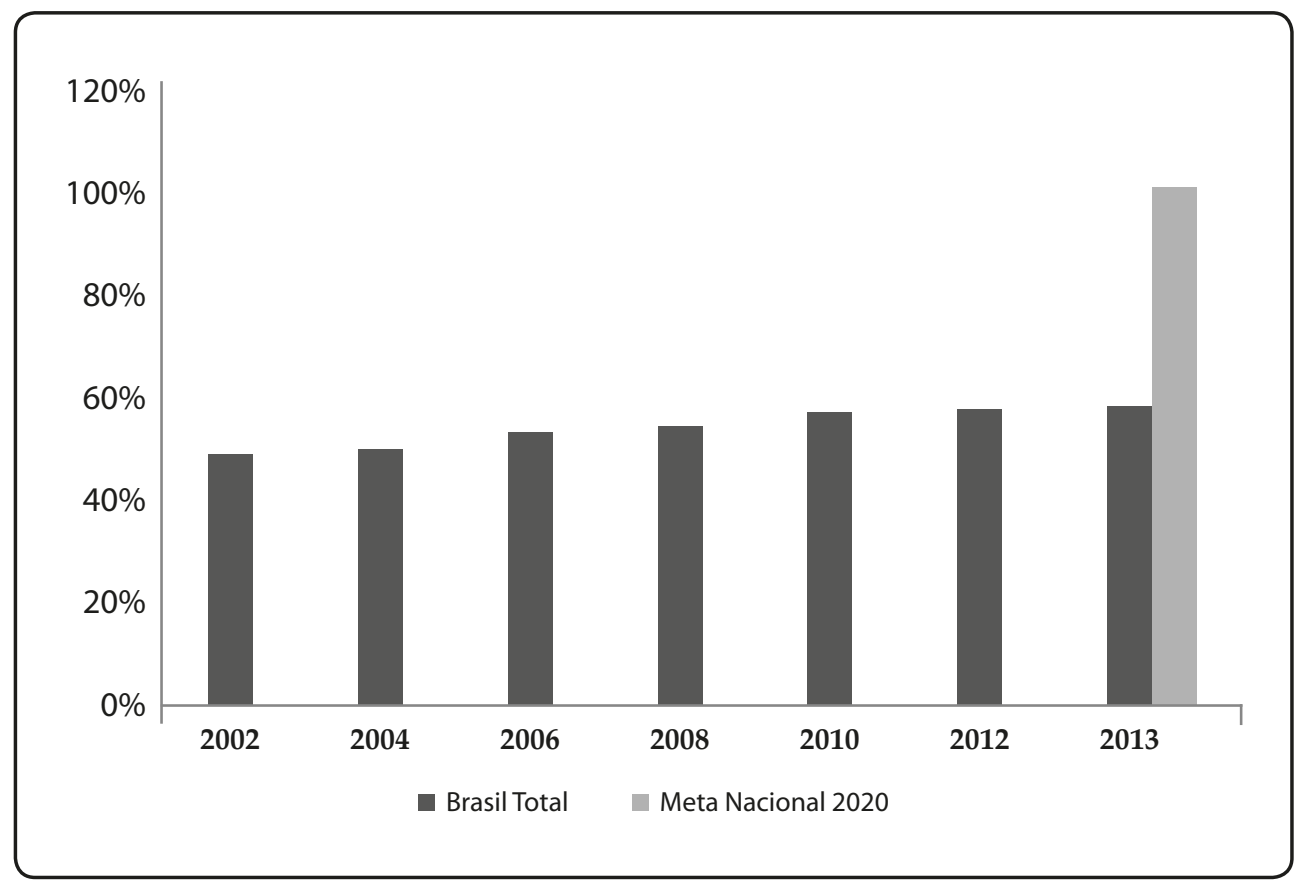

Fonte: Observatório do PNE (2016), com base nos dados do IBGE/Pnad (2013).

O que se observa, a partir dos dados, é que o rendimento dos professores vem progredindo; no entanto, o gráfico revela que, em 2013, eles recebiam apenas 57,3\% em relação ao vencimento de outros profissionais com nível superior. A meta é que em 2020 todos os professores possam atingir um rendimento compatível com as demais profissões. A projeção é imprescindível para que a valorização da carreira do magistério realmente aconteça, sob o risco de que os jovens não se interessem em seguir a profissão.

Na última Sinopse Estatística da Educação Superior, apresentada pelo Instituto Nacional de Estudos e Pesquisas Educacionais Anísio Teixeira (Inep), de 2013, foi evidenciado que há o triplo de procura pelos bacharelados em relação às licenciaturas. $\mathrm{O}$ dado indica o desinteresse pelo magistério, comprometendo a oferta futura desses 
profissionais, considerando-se que há necessidade de ampliação da educação em todos os níveis e modalidades.

A equiparação salarial do professor com as demais profissões é condição indispensável para a atratividade e permanência na carreira, pois é a questão que mais determina a escolha dos jovens, embora isso não seja suficiente. Gatti et al. (2010) destacam, a partir de pesquisa com jovens concluintes do ensino mMédio, que $83 \%$ deles não têm interesse em ser professor. Dentre os fatores negativos da profissão que justificam o fato de não escolherem ser professor estão: a) a falta de identificação pessoal (48\%); b) a baixa remuneração (25\%); c) a falta de identificação profissional (19\%); d) a desvalorização social da profissão (13\%); e) a exigência de envolvimento pessoal na profissão (10\%); f) o desinteresse e desrespeito dos alunos (10\%); e g) as condições de trabalho (6\%).

Essas questões indicam um cenário preocupante em relação à atratividade e permanência dos professores no magistério. Desse modo, torna-se necessário explicitar e problematizar a realidade da remuneração docente nos estados brasileiros, questão que será abordada na seção seguinte.

\section{A remuneração dos professores das redes estaduais de ensino}

Os estados brasileiros apresentam realidades muito discrepantes, determinadas pelo desenvolvimento econômico, social e educacional de cada região a que pertencem, interferindo nas condições de trabalho e remuneração docente. A tripla vinculação dos recursos públicos para a educação (impostos, salário-educação e percentual do Produto Interno Bruto (PIB) contribuem para a definição de políticas públicas no campo da educação. Além disso, as prioridades dos governos interferem na relação, nem sempre equilibrada, entre a vertente social (educação, saúde, habitação, saneamento, assistência social, entre outros) e a vertente econômica (salvamento de bancos, instalação de fábricas, subsídios para indústria e agricultura, renúncia fiscal etc.). (OLIVEIRA, 1988).

Podemos observar como se dá a participação das regiões no PIB do Brasil, no gráfico a seguir. 
Gráfico 2 - Percentual de participação das regiões no PIB brasileiro - 2012

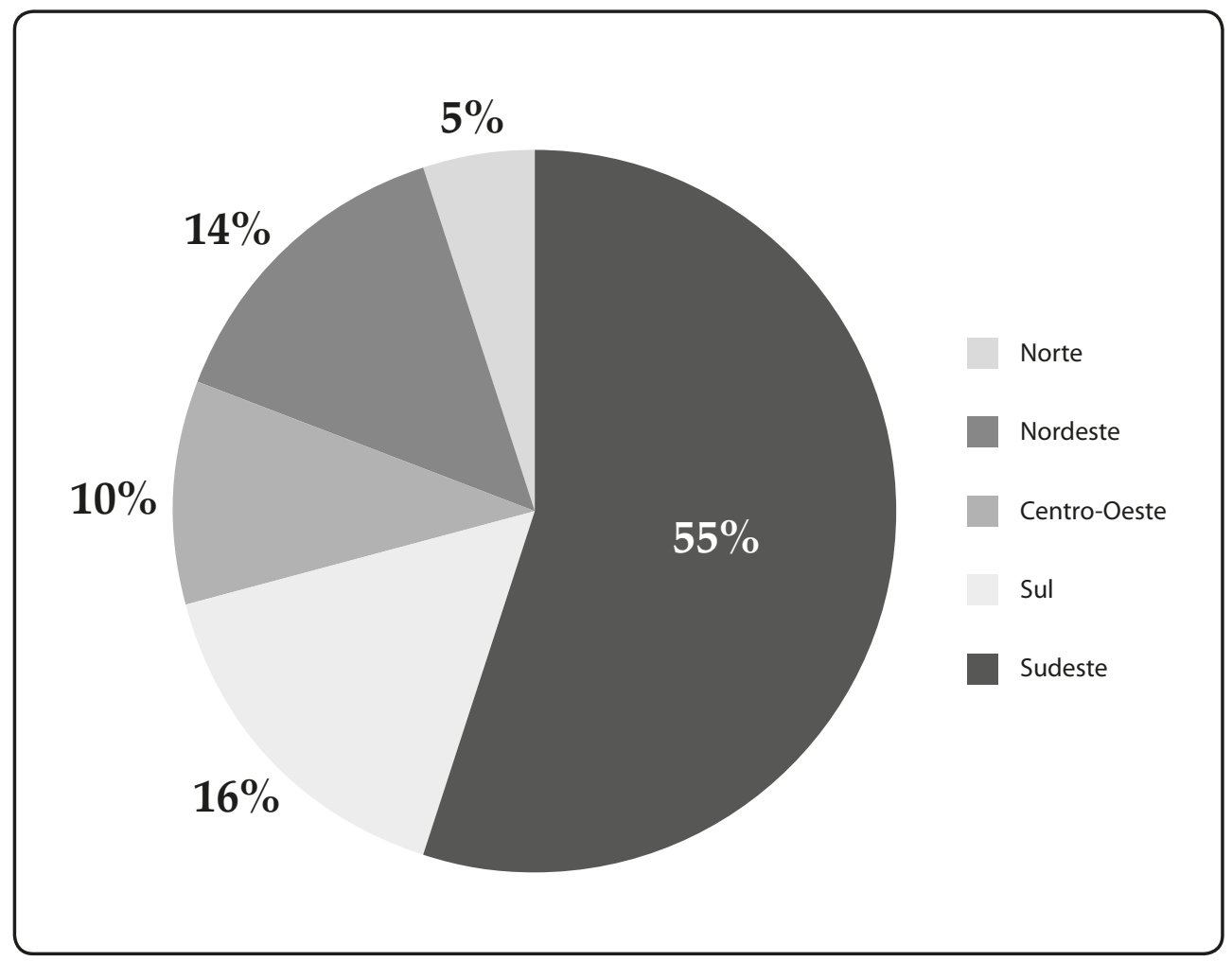

Fonte: IBGE (2012)

Destaca-se que as regiões Sul e Sudeste contribuem mais no montante do PIB nacional, no entanto, a vantagem da Região Sudeste é 3,43 vezes maior do que a Sul. Enfatizamos que todos os estados da região sul e dois da Região Sudeste consideraram que a Lei do Piso era inconstitucional, por entenderem que seria uma violação no princípio federativo da autonomia.

Para um melhor entendimento das desigualdades entre os estados, a tabela a seguir apresenta dados do Índice de Desenvolvimento Humano (IDHM), Índice de Desenvolvimento da Educação Básica (Ideb), e Produto Interno (PIB) per capita dividido pelo número de habitantes de cada estado. 
Tabela 1 - Relação entre IDHM, IDEB, e PIB per capita dos estados e do Distrito Federal.

\begin{tabular}{|l|c|c|c|c|}
\hline Estado & IDHM & IDEB - EF & IDEB - EM & PIB Per Capita \\
\hline Distrito Federal & 0.824 & 4.4 & 4.0 & 64.653 \\
\hline São Paulo & 0.783 & 4.7 & 4.1 & 33.624 \\
\hline Santa Catarina & 0.774 & 4.5 & 4.0 & 27.772 \\
\hline Rio De Janeiro & 0.761 & 4.3 & 4.0 & 31.065 \\
\hline Paraná & 0.749 & 4.3 & 3.8 & 24.195 \\
\hline Rio Grande do Sul & 0.746 & 4.2 & 3.9 & 25.779 \\
\hline Espírito Santo & 0.740 & 4.2 & 3.8 & 29.996 \\
\hline Goiás & 0.735 & 4.7 & 4.0 & 20.184 \\
\hline Minas Gerais & 0.731 & 4.8 & 3.8 & 20.325 \\
\hline Mato Grosso do Sul & 0.729 & 4.1 & 3.6 & 21.744 \\
\hline Mato Grosso & 0.725 & 4.4 & 3.0 & 25.946 \\
\hline Amapá & 0.708 & 3.6 & 3.0 & 14.915 \\
\hline Roraima & 0.707 & 3.7 & 3.4 & 15.577 \\
\hline Tocantins & 0.699 & 3.9 & 3.3 & 13.776 \\
\hline Rondônia & 0.690 & 3.9 & 3.6 & 18.466 \\
\hline Rio Grande do Norte & 0.684 & 3.6 & 3.1 & 12.249 \\
\hline Ceará & 0.682 & 4.4 & 3.6 & 10.473 \\
\hline Amazonas & 0.674 & 3.9 & 3.2 & 17.856 \\
\hline Pernambuco & 0.673 & 3.8 & 3.8 & 13.138 \\
\hline Sergipe & 0.665 & 3.2 & 3.2 & 13.181 \\
\hline Acre & 0.663 & 4.4 & 3.4 & 12.690 \\
\hline Bahia & 0.660 & 3.4 & 3.0 & 11.832 \\
\hline Paraíba & 0.658 & 3.5 & 3.3 & 10.152 \\
\hline Piauí & 0.646 & 4.0 & 3.3 & 8.138 \\
\hline Pará & 0.646 & 3.6 & 2.9 & 11.679 \\
\hline Maranhão & 0.639 & 3.6 & 3.0 & 8.760 \\
\hline Alagoas & 0.631 & 3.1 & 3.0 & 9.333 \\
\hline & & & & \\
\hline
\end{tabular}

Fonte: Inep/Ideb (2013), Atlas do Desenvolvimento Humano/IDHM (2010), IBGE/PIB per capita (2012).

Os dados mostram que há uma forte relação entre o PIB per capita e o desenvolvimento humano do estado, assim como o Ideb, mas essa tendência não é determinante. No caso do Acre e do Ceará, por exemplo, em que há um baixo PIB per capita, o Ideb do ensino fundamental corresponde ao do Distrito Federal, que apresenta o maior PIB per capita e o primeiro lugar no IDHM.

Do mesmo modo, a remuneração docente, nos diferentes estados, não está diretamente relacionada ao desenvolvimento econômico e social, embora seja possível afirmar 
que há uma tendência de que os mais desenvolvidos tenham condições de melhor remunerar os professores.

Os dados que apresentaremos em relação ao vencimento inicial e a remuneração final foram obtidos por meio do contato com as secretarias de educação dos estados e do Distrito Federal, com os sindicatos de professores, bem como pelos editais de concurso público. A partir da pesquisa, organizamos a tabela a seguir, que sintetiza informações referentes à jornada de trabalho, hora-atividade, cumprimento da lei do piso e o número da lei que regulamenta os planos de carreira dos professores que atuam nas redes estaduais de ensino, nos anos finais do ensino fundamental e no ensino médio.

\section{Tabela 2 - Vencimento inicial, jornada de trabalho, cumprimento da lei do piso e leis que regulamentam os planos de carreira dos professores dos estados brasileiros}

\begin{tabular}{|c|c|c|c|c|c|}
\hline UF & $\begin{array}{l}\text { Vencimento } \\
\text { inicial, nível } \\
\text { superior, } \\
\text { calculado para } \\
\text { uma jornada } \\
\text { de } 40 \mathrm{~h}\end{array}$ & $\begin{array}{l}\text { Carga } \\
\text { Horária }\end{array}$ & $\begin{array}{l}\text { \% de hora } \\
\text { atividade }\end{array}$ & $\begin{array}{l}\text { Cumprimento } \\
\text { da Lei } n^{0} 11.738, \\
\text { de } 2008 \\
\text { Piso/Hora ativ. }\end{array}$ & $\begin{array}{l}\text { Lei que regulamenta } \\
\text { o Plano de Carreira }\end{array}$ \\
\hline $\mathrm{AC}$ & $\mathrm{R} \$ 2.681,26$ & $30 \mathrm{~h}$ & $33 \%$ & SS & Lei $\mathrm{n}^{\circ}$ 67, de 1999 \\
\hline AL & $\mathrm{R} \$ 2.651,84$ & $40 \mathrm{~h}$ & $25 \%$ & $\mathrm{SN}$ & Lei no 6.197, de 2000 \\
\hline AM & $\mathrm{R} \$ 3.269,49$ & $40 \mathrm{~h}$ & $33 \%$ & SS & Lei no 3.951, de 2013 \\
\hline $\mathrm{AP}$ & $\mathrm{R} \$ 1.361,20$ & $40 \mathrm{~h}$ & $40 \%$ & NS & Lei no 949, de 2005 \\
\hline BA & $\mathrm{R} \$ 1.669,94$ & $40 \mathrm{~h}$ & $30 \%$ & NN & Lei $n^{\circ}$ 8.261/2002 \\
\hline $\mathrm{CE}$ & $\mathrm{R} \$ 1.815,54$ & $40 \mathrm{~h}$ & $33 \%$ & SS & Lei $n^{\circ}$ 12.066, de 1993 \\
\hline DF & $\mathrm{R} \$ 3.858,87$ & $40 \mathrm{~h}$ & $37,5 \%$ & SS & Lei $n^{\circ}$ 5.105, de 2013 \\
\hline ES & $\mathrm{R} \$ 3.475,96$ & $25 \mathrm{~h}$ & $33 \%$ & SS & Lei no 5.580 , de 1998 \\
\hline GO & $\mathrm{R} \$ 2.904,45$ & $40 \mathrm{~h}$ & $30 \%$ & $\mathrm{SN}$ & Lei no 13.909 , de 2001 \\
\hline MA & $\mathrm{R} \$ 2.443,84$ & $40 \mathrm{~h}$ & $30 \%$ & SN & Lei no 9.664, de 2012 \\
\hline MG & $\mathrm{R} \$ 2.425,50$ & $24 \mathrm{~h}$ & $33 \%$ & SS & Lei no 15.293 , de 2004 \\
\hline MS & $\mathrm{R} \$ 3.994,20$ & $40 \mathrm{~h}$ & $25 \%$ & $\mathrm{SN}$ & Lei nº 87, de 2000 \\
\hline MT & $\mathrm{R} \$ 3.916,96$ & $30 \mathrm{~h}$ & $33 \%$ & SS & Lei n⿳ำ 50, de 1998 \\
\hline PA & $\mathrm{R} \$ 1.927,37$ & $40 \mathrm{~h}$ & $25 \%$ & $\mathrm{SN}$ & Lei n⿳으‥442, de 2010 \\
\hline PB & $\mathrm{R} \$ 2.128,49$ & $30 \mathrm{~h}$ & $33 \%$ & SS & Lei no 7.419, de 2003 \\
\hline PE & $\mathrm{R} \$ 2.149,29$ & $40 \mathrm{~h}$ & $33 \%$ & SS & Lei no 11.559 , de 1998 \\
\hline PI & $\mathrm{R} \$ 2.634,65$ & $40 \mathrm{~h}$ & $33 \%$ & SS & Lei nº 71, de 2006 \\
\hline PR & $\mathrm{R} \$ 2.473,22$ & $40 \mathrm{~h}$ & $33 \%$ & SS & Lei nº 103, de 2004 \\
\hline RJ & $\mathrm{R} \$ 2.948,33$ & $30 \mathrm{~h}$ & $25 \%$ & $\mathrm{SN}$ & Lei $n^{0}$ 1614, de 1990 \\
\hline RN & $\mathrm{R} \$ 2.684,86$ & $30 \mathrm{~h}$ & $33 \%$ & SS & Lei $n^{0}$ 322, de 2006 \\
\hline $\mathrm{RO}$ & $\mathrm{R} \$ 2.016,51$ & $40 \mathrm{~h}$ & $33 \%$ & SS & Lei n⿳o 680, de 2012 \\
\hline RR & $\mathrm{R} \$ 3.548,94$ & $25 \mathrm{~h}$ & $33 \%$ & SS & Lei $\mathrm{n}^{\circ}$ 892, de 2013 \\
\hline RS & $\mathrm{R} \$ 2.331,38$ & $40 \mathrm{~h}$ & $13 \%$ & $\mathrm{SN}$ & Lei $\mathrm{n}^{\circ}$ 6.672, de 1974 \\
\hline
\end{tabular}




\begin{tabular}{|c|c|c|c|c|c|}
\hline UF & $\begin{array}{l}\text { Vencimento } \\
\text { inicial, nível } \\
\text { superior, } \\
\text { calculado para } \\
\text { uma jornada } \\
\text { de } 40 \mathrm{~h}\end{array}$ & $\begin{array}{l}\text { Carga } \\
\text { Horária }\end{array}$ & $\begin{array}{l}\% \text { de hora } \\
\text { atividade }\end{array}$ & $\begin{array}{c}\text { Cumprimento } \\
\text { da Lei } \text { n }^{0} 11.738, \\
\text { de } 2008 \\
\text { Piso/Hora ativ. }\end{array}$ & $\begin{array}{l}\text { Lei que regulamenta } \\
\text { o Plano de Carreira }\end{array}$ \\
\hline SC & $\mathrm{R} \$ 1.814,80$ & $40 \mathrm{~h}$ & $20 \%$ & $\mathrm{SN}$ & Lei no 1.139 , de 1992 \\
\hline SE & $\mathrm{R} \$ 1.943,53$ & $40 \mathrm{~h}$ & $37,5 \%$ & SS & Lei nº 61, de 2001 \\
\hline SP & $\mathrm{R} \$ 2.415,89$ & $40 \mathrm{~h}$ & $20 \%$ & SN & Lei no 836, de 1997 \\
\hline TO & $\mathrm{R} \$ 3.582,62$ & $40 \mathrm{~h}$ & $40 \%$ & SS & Lei no 2.859 , de 2014 \\
\hline
\end{tabular}

Fonte: Secretarias de Educação, editais de concurso e Sindicatos de Professores (2014).

Os dados indicam que das 27 (vinte e sete) unidades federativas, 16 (dezesseis) cum-

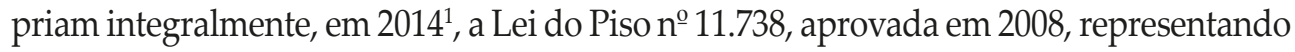
somente 59\% do total. Em relação ao estado que apresenta o melhor vencimento inicial (Mato Grosso do Sul) e o que possui o pior vencimento (Amapá) a diferença é de quase três vezes, ou seja, o menor vencimento corresponde a $34 \%$ do maior.

A carga horária de hora-atividade estipulada para os professores na Lei do Piso Salarial Profissional Nacional é de 33\%, contudo, alguns estados garantem a realização de um percentual menor, como é o caso da Bahia (30\%), Alagoas (25\%), Maranhão (30\%), Pará (25\%), Rio de Janeiro (25\%), Mato Grosso do Sul (25\%), Goiás (30\%), Rio Grande do Sul (13\%), Santa Catarina (20\%) e São Paulo (20\%). Apesar disso, o Distrito Federal $(37,5 \%)$, o Sergipe (37,5\%), o Amapá (40\%) e o Tocantins (40\%) garantem um percentual maior para a hora-atividade.

Na tabela a seguir, apresentamos o vencimento inicial e a remuneração final dos professores das redes estaduais, referentes aos anos de 2014 e 2015.

\section{Tabela 3 - Vencimento inicial (graduação) e remuneração final (doutorado) dos professores das unidades federativas do Brasil - 2014/2015 - Proporcional a 40 horas semanais}

\begin{tabular}{|l|l|c|c}
\hline Região & Estado & Vencimento Inicial & Remuneração Final \\
\hline Nordeste & Bahia & $\mathrm{R} \$ 1.669,94$ & $\mathrm{R} \$ 11.649,25$ \\
\hline Norte & Roraima & $\mathrm{R} \$ 3.548,94$ & $\mathrm{R} \$ 11.245,61$ \\
\hline Nordeste & Rio Grande do Norte & $\mathrm{R} \$ 2.684,86$ & $\mathrm{R} \$ 10.948,30$ \\
\hline Norte & Amazonas & $\mathrm{R} \$ 3.269,49$ & $\mathrm{R} \$ 10.923,95$ \\
\hline Sudeste & São Paulo & $\mathrm{R} \$ 2.415,89$ & $\mathrm{R} \$ 10.029,23$ \\
\hline Sudeste & Rio de Janeiro & $\mathrm{R} \$ 2.948,33$ & $\mathrm{R} \$ 10.027,02$ \\
\hline Sudeste & Espírito Santo & $\mathrm{R} \$ 3.475,96$ & $\mathrm{R} \$ 9.710,44$ \\
\hline Centro-oeste & Mato Grosso & $\mathrm{R} \$ 3.916,96$ & $\mathrm{R} \$ 9.549,54$ \\
\hline
\end{tabular}




\begin{tabular}{|l|l|c|c}
\hline Região & Estado & Vencimento Inicial & Remuneração Final \\
\hline Centro-oeste & Goiás & $\mathrm{R} \$ 2.904,45$ & $\mathrm{R} \$ 8.666,61$ \\
\hline Nordeste & Maranhão & $\mathrm{R} \$ 2.443,84$ & $\mathrm{R} \$ 7.499,68$ \\
\hline Norte & Tocantins & $\mathrm{R} \$ 3.582,62$ & $\mathrm{R} \$ 7.275,87$ \\
\hline Centro-oeste & Distrito Federal & $\mathrm{R} \$ 3.858,87$ & $\mathrm{R} \$ 6.862,49$ \\
\hline Nordeste & Sergipe & $\mathrm{R} \$ 1.943,53$ & $\mathrm{R} \$ 6.478,03$ \\
\hline Norte & Acre & $\mathrm{R} \$ 2.681,26$ & $\mathrm{R} \$ 6.113,29$ \\
\hline Nordeste & Ceará & $\mathrm{R} \$ 1.815,54$ & $\mathrm{R} \$ 6.075,72$ \\
\hline Sul & Rio Grande do Sul & $\mathrm{R} \$ 2.331,38$ & $\mathrm{R} \$ 5.670,90$ \\
\hline Norte & Amapá & $\mathrm{R} \$ 5.545,47$ \\
\hline Nordeste & Pernambuco & $\mathrm{R} \$ 1.361,20$ & $\mathrm{R} \$ 5.374,73$ \\
\hline Sudeste & Minas Gerais & $\mathrm{R} \$ 2.149,29$ & $\mathrm{R} \$ 5.017,16$ \\
\hline Nordeste & Piauí & $\mathrm{R} \$ 2.425,50$ & $\mathrm{R} \$ 4.975,92$ \\
\hline Norte & Pará & $\mathrm{R} \$ 2.634,65$ & $\mathrm{R} \$ 3.974,26$ \\
\hline Sul & Santa Catarina & $\mathrm{R} \$ 1.927,37$ & $\mathrm{R} \$ 3.930,61$ \\
\hline Norte & Rondônia & $\mathrm{R} \$ 1.814,80$ & $\mathrm{R} \$ 3.556,96$ \\
\hline Nordeste & Paraíba & $\mathrm{R} \$ 2.016,51$ & $\mathrm{R} \$ 3.112,93$ \\
\hline Nordeste & Alagoas & $\mathrm{R} \$ 2.128,49$ & $\mathrm{R} \$ 4.327,85$ (Mestrado) \\
\hline Centro-oeste & Mato Grosso do Sul & $\mathrm{R} \$ 3.994,20$ & $\mathrm{R} \$ 7.037,73$ (Mestrado) \\
\hline Sul & Paraná & $\mathrm{R} \$ 2.473,22$ & $\mathrm{R} \$ 12.919,44$ (PDE) \\
\hline
\end{tabular}

Fonte: secretarias de educação, editais de concurso e sindicatos de professores (2014/2015).

A tabela foi organizada na ordem decrescente, considerando-se a remuneração final dos professores, mas os três últimos estados não preveem, no plano de carreira, a formação em nível de doutorado. Alagoas e Mato Grosso do Sul consideram a formação até o nível de mestrado e o Paraná possui um Programa de Desenvolvimento Educacional (PDE), que se destina à formação continuada dos professores do quadro próprio do magistério (QPM) e que se encontram no nível II, classe 8 a 11, da tabela de vencimentos do plano de carreira. Tal programa possibilita que a titulação dos cursos de mestrado e/ ou doutorado seja aproveitada para a obtenção da certificação do PDE.

Os dados sobre o vencimento inicial apresentados na tabela anterior, podem ser mais bem comparados no gráfico a seguir. 


\section{Gráfico 3 - Vencimento inicial, com nível superior, jornada de 40 horas semanais - 2014/2015.}

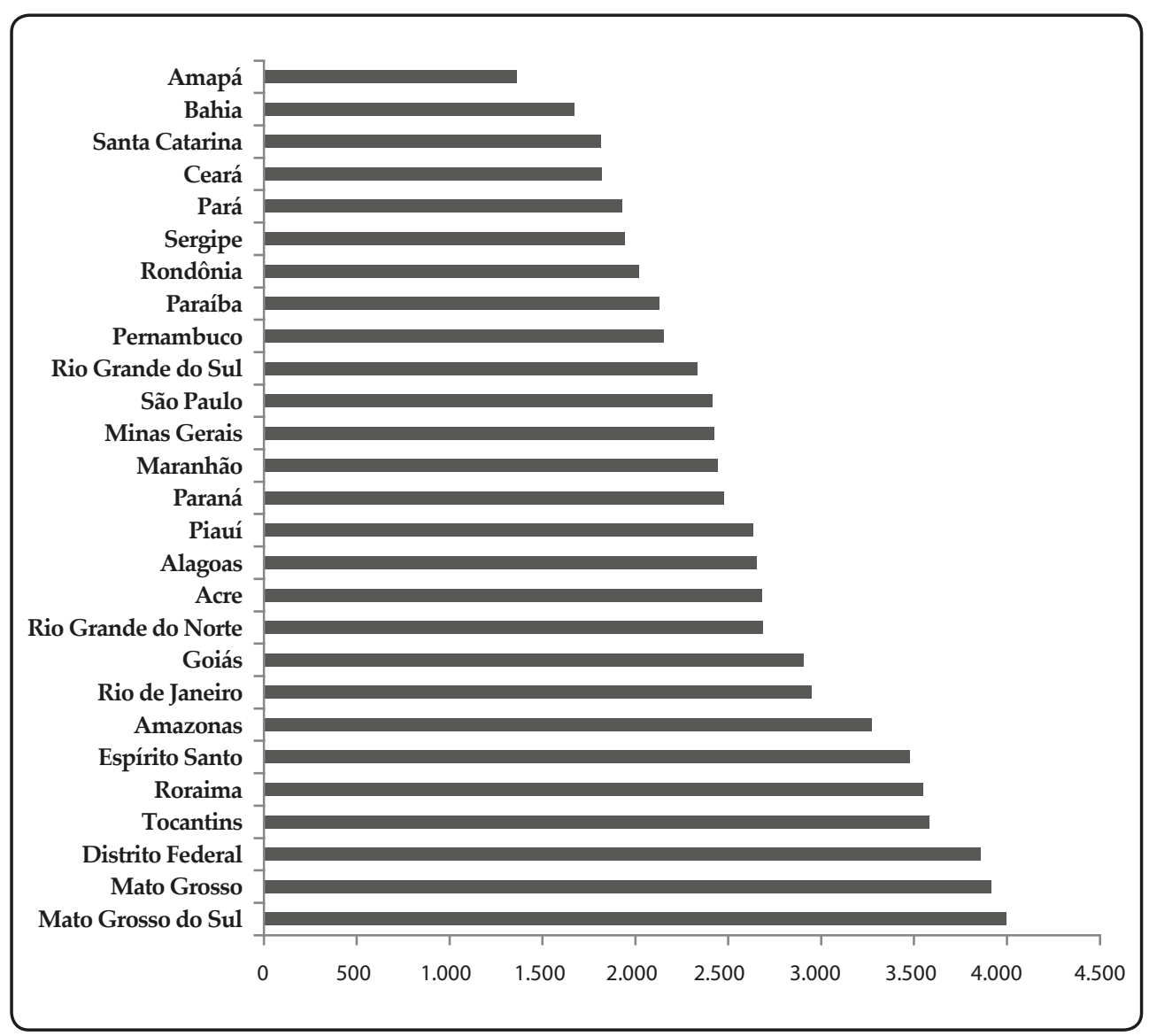

Fonte: secretarias de educação, editais de concurso e sindicatos de professores (2014/2015).

Nesse gráfico percebemos que os estados das regiões Sul e Sudeste, com maior participação no PIB nacional, não apresentam as melhores colocações no que se refere ao vencimento inicial dos professores, evidenciando que a atratividade para o ingresso na carreira é maior nos seguintes estados: Mato Grosso do Sul, Mato Grosso, Distrito Federal, Tocantins e Roraima, respectivamente.

No gráfico a seguir, apresentamos a remuneração final, com base no título de doutorado, para uma jornada de 40 (quarenta) horas semanais. Destaca-se o fato de que Alagoas e Mato Grosso do Sul consideram somente a formação em nível de mestrado e o Paraná possui o PDE, em que somente os que participarem do programa de formação continuada podem chegar ao último nível da carreira. 


\section{Gráfico 4 - Remuneração final, com doutorado, jornada de 40 horas semanais - 2014/2015.}

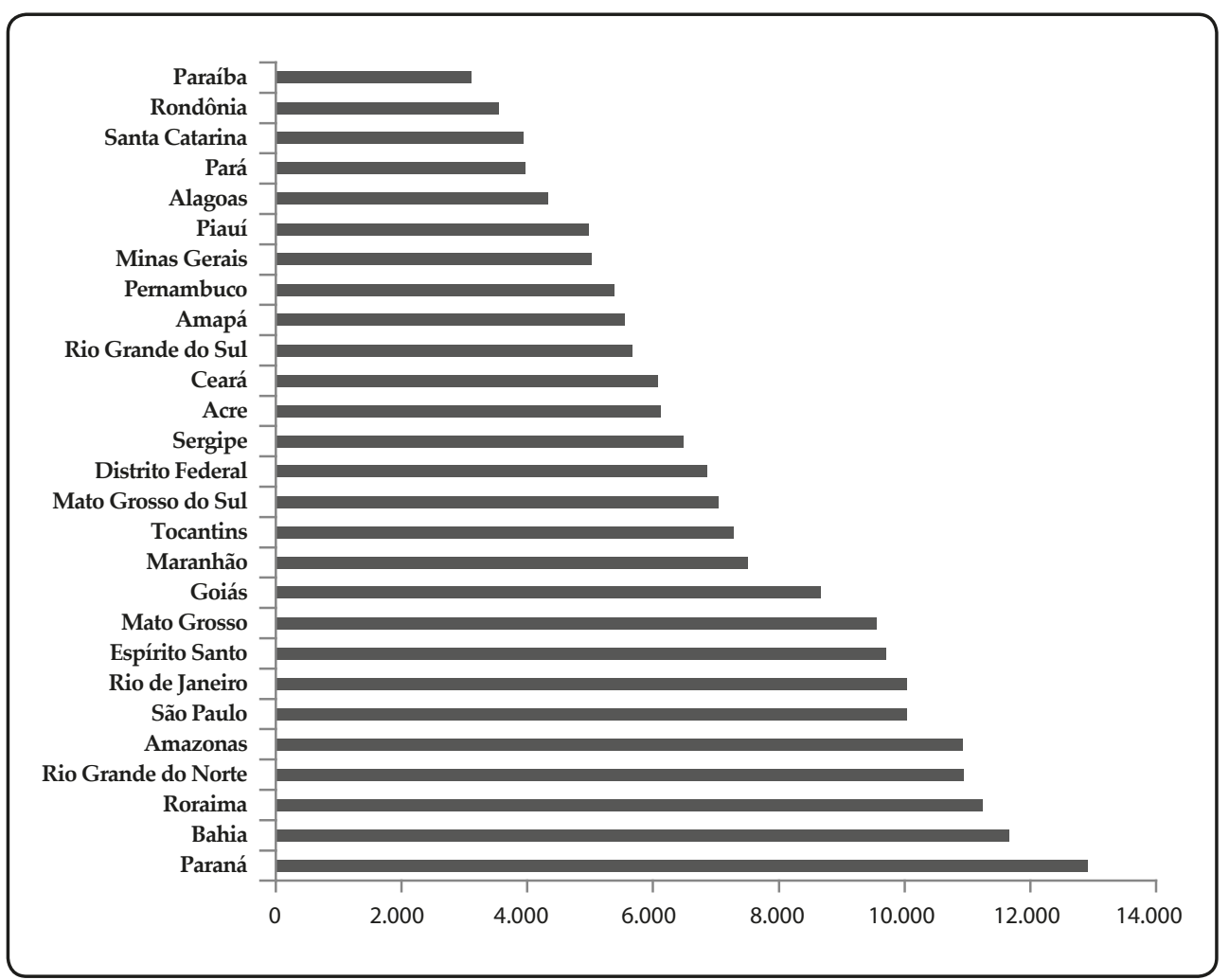

Fonte: Secretarias de Educação, editais de concurso e Sindicatos de Professores (2014/2015).

Nesse gráfico, constatamos que os estados que apresentam maior atratividade para a permanência na profissão são: Paraná, Bahia, Roraima, Rio Grande do Norte e Amazonas, respectivamente. Somente um estado do Sul e nenhum do Sudeste se encontra nas cinco primeiras colocações, embora, como já destacamos, são as regiões que mais contribuem com o PIB nacional.

Não obstante, a relação entre remuneração e custo de vida também deve ser considerada, uma vez que a média do custo de vida de cada estado varia muito, conforme a região em que ele se encontra. Os estados que apresentam as capitais com maior custo de vida não são os que melhor remuneram os seus professores ${ }^{3}$. Desse modo, a comparação entre a remuneração dos professores dos diferentes estados não prescinde desta questão, pois pode parecer que um estado remunera melhor que outro, porém, seu custo de vida é superior ao dos demais.

Há muitas diferenças no vencimento inicial e na remuneração ao final da carreira. Numa mesma região, há disparidades significativas, como é o caso da Bahia e da Paraíba, 
pois o segundo é o estado que pior remunera um professor com doutorado, enquanto a Bahia se encontra na segunda colocação, embora não cumprisse com o piso salarial em 2014. Vale destacar que a Lei no 11.738 definiu o Piso Salarial Profissional Nacional para professores com nível médio, com uma jornada de 40 (quarenta) horas semanais. Em 2014, estados pagavam pouco mais que o piso, mas exigiam formação de nível superior para ingressar na carreira, como é caso de Santa Catarina, Sergipe, Pará, Ceará e Bahia.

Outra questão a ser destacada na análise dos dados é a falta de atratividade ao longo da carreira do professor. No estado da Paraíba, por exemplo, o professor inicia a carreira ganhando $\mathrm{R} \$ 2.128,49$, e chega ao final recebendo apenas $\mathrm{R} \$ 3.112,93$. Isso pode contribuir para o abandono da profissão, pois, de acordo com Lemos (2009), os principais motivos são a desvalorização profissional, a indisciplina e violência dos alunos, os salários baixos, o ambiente negativo de trabalho, a progressão pouco atrativa na carreira, as famílias desinteressadas dos alunos, as condições de trabalho, dentre outros.

Embora em muitos estados o professor inicie a carreira ganhando menos que outras profissões com o mesmo nível de formação, um plano de carreira que valorize adequadamente a formação continuada e o tempo de serviço do professor podem contribuir para a permanência na profissão. O cálculo do coeficiente de progressão permite observar quantas vezes mais é a remuneração final em relação ao vencimento inicial.

\section{Tabela 4 - Coeficiente de progressão na carreira docente nos estados brasileiros}

\begin{tabular}{l|l|c}
\hline Região & Estado & Coeficiente \\
\hline Nordeste & Bahia & 6,1 \\
\hline Sul & Paraná & 5,2 \\
\hline Sudeste & São Paulo & 4,1 \\
\hline Nordeste & Rio Grande do Norte & 4,0 \\
\hline Norte & Amapá & 4,0 \\
\hline Sudeste & Rio de Janeiro & 3,4 \\
\hline Nordeste & Ceará & 3,3 \\
\hline Norte & Amazonas & 3,3 \\
\hline Nordeste & Sergipe & 3,3 \\
\hline Norte & Roraima & 3,1 \\
\hline Nordeste & Maranhão & 3,0 \\
\hline Centro-oeste & Goiás & 2,9 \\
\hline Nordeste & Pernambuco & 2,5 \\
\hline Centro-oeste & Mato Grosso & 2,4 \\
\hline Sul & Rio Grande do Sul & 2,4 \\
\hline Norte & Acre & 2,2 \\
\hline Sudeste & Espírito Santo & 2,2 \\
\hline
\end{tabular}




\begin{tabular}{l|l|c}
\hline Região & Estado & Coeficiente \\
\hline Sul & Santa Catarina & 2,1 \\
Sudeste & Minas Gerais & 2,0 \\
Norte & Pará & 2,0 \\
\hline Nordeste & Piauí & 1,8 \\
Norte & Tocantins & 1,8 \\
\hline Centro-oeste & Distrito Federal & 1,7 \\
Centro-oeste & Mato Grosso do Sul & 1,7 \\
Norte & Rondônia & 1,7 \\
Nordeste & Alagoas & 1,6 \\
\hline Nordeste & Paraíba & 1,4 \\
\hline
\end{tabular}

Fonte: secretarias de educação, editais de concurso e sindicatos de professores (2014/2015).

Percebemos, portanto, que não há um adequado estímulo para a permanência na profissão na maioria dos estados. Para Cirilo (2012, p. 105), “[...] a carreira pode ser entendida como as etapas que o trabalhador vai galgando a partir do ingresso, para atingir o ápice do caminho. Além disso, consiste no mecanismo de estímulo ao exercício da profissão já que refuta a ideia de estagnação". Desse modo, a estagnação na carreira é um elemento decisivo para o abandono da profissão.

Dados da Organização para a Cooperação e Desenvolvimento Econômico (OCDE) confirmam essa realidade, destacando que, no Brasil, a média dos salários dos professores é quase três vezes menor do que os demais países analisados. A pesquisa, denominada de Education at a Glance 2014: OCDE Indicators, foi realizada com 35 (trinta e cinco) países membros da OCDE e também com os 10 (dez) países parceiros, como é o caso do Brasil (OCDE, 2014).

Embora a remuneração dos professores tenha melhorado, nos últimos anos, especialmente com a aprovação da Lei do Piso, a situação ainda é complicada e os esforços para modificar essa realidade não foram suficientes. Muitos estados, após a aprovação dessa lei, têm aplicado a interpretação do valor mínimo como se fosse o máximo, mesmo em condição de garantir melhor remuneração aos professores. Além disso, a lei estabelece o mínimo a ser pago para os que possuem somente o nível médio de formação, indicando que não há uma valorização condizente com a formação inicial dos professores nas redes estaduais de ensino.

A mudança dessa situação requer clareza da realidade e que busquemos publicizá-la, a fim de contribuir para a luta por mais investimentos não só em formação, mas também na remuneração dos professores. $O$ fortalecimento dos sindicatos de professores é um caminho importante para aprofundar e impulsionar as mudanças necessárias para que, de fato, esses profissionais sejam valorizados no Brasil. 


\section{Considerações finais}

Buscamos apresentar um mapa geral da valorização dos professores que trabalham nas redes estaduais de ensino no Brasil. Detivemos-nos a analisar a questão da remuneração por considerar que, em última instância, é o fator que mais contribui para a atratividade no acesso e na permanência na profissão.

Os dados revelam as disparidades regionais e suas relações com a valorização dos professores. Embora o desenvolvimento econômico dos estados interfira decisivamente no desenvolvimento humano e social, conforme os dados do IDHM, essa tendência não se confirma em relação à remuneração dos professores, pois somente três estados das regiões Sul e Sudeste estão entre os dez que apresentam maior coeficiente de progressão na carreira.

Diante da realidade, há necessidade de um progressivo aumento da remuneração ao longo da carreira, de modo que a diferença entre o início e o final não seja pouco atrativa. Além do mais, a meta do PNE de equiparar o salário do professor com outros profissionais, até 2020, caso seja alcançada, poderá representar maior valorização social do professor.

Ao lado da mobilização nacional pela aprovação de leis que garantam melhores condições de formação, trabalho e remuneração, é fundamental a organização dos professores em defesa do cumprimento delas em cada estado e a conquista de novas possibilidades de efetiva valorização social da profissão.

Recebido em abril de 2016 e aprovado em junho de 2016

\section{Notas}

1 Em 2014, o valor do Piso Salarial Profissional Nacional era R\$ 1.697,00.

2 Não foi possível obter dados atualizados do estado do Amapá, no entanto, informação disponível no Portal da Transparência indica que um professor contrato em 2014, teve como vencimento inicial o valor de $\mathrm{R} \$$ 3.132,97.

3 Capitais com maior custo de vida: São Paulo - SP, Brasília - DF, Rio de Janeiro - RJ, Florianópolis - SC (DIEESE, 2016). 


\section{Referências}

ATLAS DO DESENVOLVIMENTO HUMANO. Índice de Desenvolvimento Humano dos Estados 2010. Disponível em: <http://www.atlasbrasil.org.br/2013/> Acesso em: 7 dez. 2015.

BRASIL. Constituição da República Federativa do Brasil de 1988. Brasília, 2013. Disponível em: <http://www.senado.gov.br/legislação/const/com1988/CON1988_05.10.1988/CON1988.pdf>. Acesso em: 7 dez. 2015.

. Emenda Constitucional no 53, de 19 de dezembro de 2006. Dá nova redação aos arts. 7ํ, 23, 30, 206, 208, 211 e 212 da Constituição Federal e ao art. 60 do Ato das Disposições Constitucionais Transitórias. Disponível em: <http://www.planalto.gov.br/ccivil_03/constituicao/Emendas/Emc/emc53. htm>. Acesso em: 13 nov. 2015.

. Lei no 9.394, de 20 de dezembro de 1996. Lei de Diretrizes e Bases da Educação Nacional. Disponível em: <http://www.planalto.gov.br/ccivil_03/leis/19394.htm>. Acesso em: 08 dez. 2015.

. Lei n⿳0 11.494, de 20 de junho de 2007. Regulamenta o Fundo de Manutenção e Desenvolvimento da Educação Básica e de Valorização dos Profissionais da Educação - FUNDEB. Disponível em: <http://www.planalto.gov.br/ccivil_03/_ato2007-2010/2007/Lei/L11494.htm>. Acesso em: 20 nov. 2015.

. Lei $\mathrm{n}^{\mathbf{0}} \mathbf{1 1 . 7 3 8}$, de 16 de julho de 2008. Regulamenta a alínea "e" do Inciso III do caput do art. 60 do Ato das Disposições Constitucionais Transitórias, para instituir o piso salarial profissional nacional para os profissionais do magistério público da educação básica. Disponível em: <http://www.planalto. gov.br/ccivil_03/_ato2007-2010/2008/lei/111738.htm> Acesso em: 3 abr. 2016.

. Lei n⿳0 13.005, de 25 de junho de 2014. Aprova o Plano Nacional de Educação - PNE e dá outras providências. Disponível em: <http://www.planalto.gov.br/ccivil_03/_Ato2011-2014/2014/Lei/L13005. htm>. Acesso em: 27 mar. 2016.

. Resolução nº 3, de 8 de outubro de 1997. Fixa as Diretrizes para os Novos Planos de Carreira e de Remuneração para o Magistério dos Estados, do Distrito Federal e dos Municípios. Disponível em: <http://portal.mec.gov.br/cne/arquivos/pdf/CEB0397.pdf>. Acesso em: 5 dez. 2015.

Resolução n⿳0 2, de 28 de maio de 2009. Fixa as Diretrizes Nacionais para os Planos de Carreira e Remuneração dos Profissionais do Magistério da Educação Básica Pública, em conformidade com o artigo $6^{0}$ da Lei $n^{0} 11.738$, de 16 de julho de 2008, e com base nos artigos 206 e 211 da Constituição Federal, nos artigos $8^{\circ}$, § $1^{\circ}$, e 67 da Lei $n^{\circ}$ 9.394, de 20 de dezembro de 1996, e no artigo 40 da Lei $n^{\circ}$ 11.494, de 20 de junho de 2007. Disponível em: <http://portal.mec.gov.br/dmdocuments/resolucao_ cne_ceb002_2009.pdf> Acesso em 13 nov. 2015.

CIRILO, P. R. As políticas de valorização docente no estado de Minas Gerais. 2012,154 f. Dissertação (Mestrado em Educação) - Faculdade de Educação, Universidade Federal de Minas Gerais, Belo Horizonte, 2012.

DIEESE. Comportamento do custo da Cesta Básica se diferencia nas capitais do Brasil. 2016. Disponível em: <http://www.dieese.org.br/analisecestabasica/2016/2016 03cestabasica.pdf > Acesso em: 15 abr. 2016.

GATTI, B. A. et al. A atratividade da carreira docente no Brasil. Estudos \& Pesquisas Educacionais, São Paulo, n.1, maio, 2010.

GOUVEIA, A. B.; SOUZA, A. R. Remuneração de professores em redes públicas no Estado do Paraná. In: CAMARGO, R. B.; JACOMINI, M. A. Vencimento e remuneração docente no Brasil: resultados de pesquisa. São Paulo: Xamã, 2015. 
INSTITUTO BRASILEIRO DE GEOGRAFIA E ESTATÍSTICA (IBGE). Participação das Grandes Regiões e Unidades da Federação no Produto Interno Bruto - 2002-2012. Disponível em: <http://www. ibge.gov.br/home/estatistica/economia/contasregionais/2012/default_xls_2002_2012.shtm> Acesso em: 15 abr. 2016.

Produto Interno Bruto par capita dos estados - 2012. Disponível em: <http://www.ibge.gov.br/ estadosat/perfil.php> Acesso em: 14 mar. 2016.

INSTITUTO NACIONAL DE ESTUDOS E PESQUISAS EDUCACIONAIS ANÍSIO TEIXEIRA (INEP). Sinopse Estatística da Educação Superior. Disponível em: <http://portal.inep.gov.br/superiorcensosuperior-sinopse> Acesso em: 14 mar. 2016.

INEP. Índice de Desenvolvimento da Educação Básica - 2013. Disponível em: <http://ideb.inep. gov.br/>. Acesso em: 14 abr. 2015.

LEMOS, J. C. G. Do encanto ao desencanto, da permanência ao abandono: o trabalho docente e a construção da identidade profissional. 2009. 315 f. Tese (Doutorado em Educação). Pontifícia Universidade Católica de São Paulo, São Paulo, 2009.

MARX, K.; ENGELS, F. A ideologia alemã: Crítica da mais recente filosofia alemã em seus representantes Feuerbach, B. Bauer e Stirner, e do socialismo alemão em seus diferentes profetas. São Paulo: Boitempo, 2007.

OBSEVATÓRIO DO PNE. Disponível em: <http://www.observatoriodopne.org.br/metas-pne/17valorizacao-professor> Acesso em: 14 mar. 2016.

OCDE. Education at a Glance 2014: OECD Indicators. 2014. Disponível em: <http://dx.doi.org/10.1787/ eag-2014-en> Acesso em: 10 dez. 2015.

OLIVEIRA, F. Os direitos do anti-valor: a economia política da hegemonia imperfeita. Petrópolis, RJ: Vozes, 1988. 


\section{The appreciation of teachers and basic education in the states}

ABSTRACT: This paper presents an overview of the situation of teachers in state schools, using documentary research, and demonstrates the discrepancy in pay in the final years of elementary school and high school, highlighting the urgent need to face the need to value these professionals who are essential to improving the quality of education.

Keywords: Educational policy. Valuing teachers. Career plans.

\section{La valorisation des professeurs et l'éducation basique dans les états}

RÉSUMÉ: L'article présente un panorama général de la situation des enseignants du réseau publique d'état d'enseignement, à travers une recherche documentaire qui montre l'écart concernant la rémunération entre les dernières années de l'enseignement fondamental et l'enseignement secondaire, mettant en évidence l'urgence d'envisager la valorisation des ces professionnels, essentielle à l'amélioration de la qualité de l'éducation.

Mots-clés: Politique éducative. Valorisation des professionnels. Plans de carrière.

\section{La valoración de los profesores y la educación básica en los estados}

RESUMEN: El artículo ofrece un panorama general de la situación de los profesores de las redes estatales de enseñanza por medio de una investigación documental, que muestra la discrepancia de remuneración en los últimos años de la enseñanza fundamental y enseñanza media. Además, el trabajo pone de manifiesto la urgente necesidad de abordar la valoración de dichos profesionales, esencial para mejorar la calidad de la educación.

Palabras clave: Política educativa. Valoración de profesores. Plan de carrera. 